Research Paper

\title{
5-aminolaevulinic acid-based photodynamic therapy inhibits ultraviolet B-induced skin photodamage
}

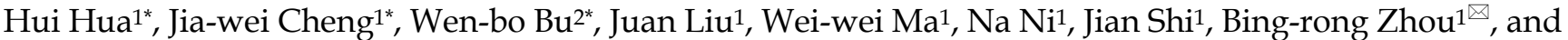 \\ Dan Luo ${ }^{1 \otimes}$ \\ 1. Department of Dermatology, The First Affiliated Hospital of Nanjing Medical University, Nanjing, China; \\ 2. Institute of Dermatology, Chinese Academy of Medical Science and Peking Union Medical College, Nanjing, China. \\ *These authors contributed equally to this work. \\ $\square$ Corresponding author: Dan Luo (daniluo2005@163.com), Bing-rong Zhou (e-mail: bingrong.2002@163.com) \\ (1) The author(s). This is an open access article distributed under the terms of the Creative Commons Attribution License (https://creativecommons.org/licenses/by/4.0/). \\ See http://ivyspring.com/terms for full terms and conditions.
}

Received: 2018.11.17; Accepted: 2019.06.21; Published: 2019.08.07

\begin{abstract}
To evaluate the photoprotective effect of 5 -aminolaevulinic acid-based photodynamic therapy (ALA-PDT) on ultraviolet B (UVB)-induced skin photodamage. In vivo experiments, the dorsal skin of hairless mice were treated with ALA-PDT or saline-PDT, and then exposed to $180 \mathrm{~mJ} / \mathrm{m}^{2} \mathrm{UVB}$. Results showed that the number of sunburn cells and apoptotic cells in the epidermis of ALA-PDT-treated groups at $24 \mathrm{~h}$ after UVB irradiation were significantly decreased compared with those in the UVB groups. And the removal rate of CPDs was obviously higher in ALA-PDT-treated groups. At $48 \mathrm{~h}$, the number of Ki67 positive nuclei in ALA-PDT-UVB group was significantly fewer than that in UVB group. Further in vitro experiments, human keratinocyte cell line $(\mathrm{HaCaT})$ cells of two groups (one treated with ALA-PDT, the other untreated), were exposed to $60 \mathrm{~mJ} / \mathrm{m}^{2}$ UVB irradiation. We found $0.5 \mathrm{mmol} / \mathrm{L}$ of ALA and $3 \mathrm{~J} / \mathrm{cm}^{2}$ of red light did not affect the vitality of cells, and could reduce UVB induced apoptosis, accelerate the clearance of CPDs, inhibit proliferation and activate $\mathrm{p} 53$. Thus, our data demonstrate that ALA-PDT pretreatment can induce a protective DNA damage response that protects skin cells from UVB-induced photodamages.
\end{abstract}

Key words: photodamage, ultraviolet radiation, photodynamic therapy, DNA damage, CPDs, p53

\section{Introduction}

Recent clinical and epidemiological studies have shown a rising incidence of skin tumors, with ultraviolet (UV) radiation acting as a high-risk environmental factor that also causes many other skin lesions[1-3], such as erythema, edema, skin pigmentation, dysplasia, photoaging and actinic keratosis[4-8]. Many processes, mainly DNA damage, are involved in UV-induced skin photodamage. Ultraviolet radiation B (UVB) is a major cause of DNA damage of epidermal cells, as evidenced by over $90 \%$ of non-melanoma skin cancers associated with excessive exposure to UVB radiation[9]. UVB may directly damage DNA, generating several types of pro-mutagenic lesions, like cyclobutane pyrimidine dimers (CPDs, a major type) and pyrimidine (6-4) pyrimidinone photoproducts ((6-4)PPs)[10-12]. If not eliminated or repaired immediately, these photoproducts may mutate skin cells and even form tumor cells.[13] A variety of signaling pathways are involved in DNA damage and repair, like P53 pathway $[6,14,15]$.

As a noninvasive drug-instrument combination technology, 5-aminolaevulinic acid-based photodynamic therapy (ALA-PDT) is combination of photosensitizer, light irradiation and oxygenation. The mechanism of PDT is that excessive amounts of exogenous ALA leads to accumulation of intracellular PpIX, production of cytotoxic reactive oxygen species (ROS) in the presence of light with appropriate wavelength, and the ultimate cell membrane destruction and apoptosis[16, 17]. At present, research focus has shifted to the mechanisms of ALA-PDT 
treating skin photodamage[18, 19], to be specific, the clearance of aged and mutated skin cells[20]. Our research has previously found that ALA-PDT induces apoptosis of photo-aged skin fibroblasts through oxidative damage[21]. In addition, other mechanisms are also engaged. For example, ALA-PDT can weaken the effect of IL-1a on keratinocyte hyperkeratosis by inhibiting the FGFR2 pathway, which is a mechanism in acne treatment[22].

ALA-PDT has been used to treat skin tumors, photoaging and other photodamage[17, 23], and prevent various photodamaged dermatoses[24, 25]. The first animal experiment, conducted in 1997 by Stender, found that ALA-PDT used on a large surface prevented hairless mouse from UV-induced skin cancers[26]. Caty V et al. also found that PDT with topical methyl aminolevulinate (MAL) used on a large surface could prevent BCCs of PTCH mice chronically exposed to UV radiation[27]. In addition to animal experiments, clinical trials have extensively reported that ALA-PDT can cure the typical multiple AK lesions and prevent AKs and skin cancers[28]. Although a large number of studies have found that ALA-PDT can prevent photodamaged dermatosis, the exact mechanism remains unknown.

Based on these research results, we carried out experiments in vivo and in vitro to explore the underlying mechanisms. We pretreated the hairless mice skin and HaCaT cells with ALA-PDT, and then exposed them to UVB to detect DNA damage repair response. The results showed that ALA-PDT significantly reduced UVB-induced DNA damage by enhancing the repairing ability of DNA-damaged skin cells, suggesting ALA-PDT can inhibit UVB-induced photodamage.

\section{Material and Methods}

\section{In vivo study}

\section{Animals}

All animal experiments were approved by the Animal Use Committee of Nanjing Medical University and performed in accordance with the committee guidelines of Nanjing Medical University. In this study, we used 30 female BALB/c athymic nude mice, aged 4-6 weeks and weighing 18-22 g, purchased from Model Animal Research Center of Nanjing University. After acclimatization, the mice were randomly divided to 3 groups (10 animals in each group): Control group (no treatment), ALA-PDT-UVB group $\left(10 \%\right.$ ALA $+12 \mathrm{~J} / \mathrm{cm}^{2}$ red light $+180 \mathrm{~mJ} / \mathrm{cm}^{2} \mathrm{UVB}$ ), UVB group (saline +180 $\left.\mathrm{mJ} / \mathrm{cm}^{2} \mathrm{UVB}\right)$.

\section{ALA-PDT treatment and UVB irradiation}

ALA was applied to a $4.0-\mathrm{cm}^{2}$-area of dorsal skin using a piece of medical cotton soaked with ALA solution (10\%; Fudan-Zhangjiang Bio-Pharmaceutical Co, China). UVB group used physiological saline as negative control. Subsequently, the treated areas were covered with layers of plastic wraps and black plastic sheets, secured with medical tape. Two hours later, these dressings were removed. The exposed tissues were irradiated by a PDT laser (XD-635AB; Fudan-Zhangjiang Bio-Pharmaceutical Co, China) with a wavelength of $635 \mathrm{~nm}$, a duration of $10 \mathrm{~min}$, and an energy density of $12 \mathrm{~J} / \mathrm{cm}^{2}$. After treated with ALA-PDT or physiological saline and a 3-day interval, mice were irradiated with UVB, with a dose of 180 $\mathrm{mJ} / \mathrm{cm}^{2}$. UVB irradiation was delivered by a UV fluorescent lamp (JCB35-24-01, Sigma, Shanghai, China). Irradiation output was monitored using a UV-meter (Philips, The Netherlands). During irradiation, mice were anesthetized with $0.4 \%$ chloral hydrate $(0.1 \mathrm{ml} / 10 \mathrm{~g})$. The dorsal skin was collected 6 $h, 24 \mathrm{~h}$ or $48 \mathrm{~h}$ after UVB irradiation for analysis.

\section{Histology}

Skin samples were sliced and fixed in $4 \%$ paraformaldehyde for routine paraffin embedding. For each specimen, a cascade of $6-\mu \mathrm{m}$ sections were prepared, mounted on glass slides, and dried overnight at $37^{\circ} \mathrm{C}$ to promote adhesion. After the sliced sections were treated with haematoxylin and eosin (H\&E), the number of sunburn cells was observed.

\section{TUNEL assay}

TUNEL assay was performed in tissue sections using the One Step TUNEL Apoptosis Assay Kit (Beyotime Biotechnology, China) according to the manufacturer's instructions. Briefly, tissue sections were deparaffinized, rehydrated followed by antigen retrieval with digestion proteinase $\mathrm{K}(20 \mu \mathrm{g} / \mathrm{ml})$ for 20 $\min$ at $37^{\circ} \mathrm{C}$. Then slides were incubated with $5 \mu \mathrm{L}$ TdT enzyme and $45 \mu \mathrm{L}$ fluorescein-dUTP for $60 \mathrm{~min}$ at $37^{\circ} \mathrm{C}$. After washing, slides were double stained with 4 ',6-diamidino-2-phenylindole (DAPI) to visualize the nuclei. For each group, the number of apoptotic cells and the sum of cells of five random fields were photographed and counted under the fluorescence microscope. The apoptotic index of the cells was calculated using the following formula: Apoptotic index $=$ apoptotic cells $/$ total cells $\times 100 \%$.

\section{Immunofluorescence (IF) analysis on CPDs}

All specimens were fixed in $4 \%$ paraformaldehyde and then embedded in paraffin. After blocking endogenous peroxides and proteins, 
sections were incubated overnight at $4^{\circ} \mathrm{C}$ with rabbit monoclonal primary antibodies against CPDs (1:500; Sigma, USA). Having been washed with PBS, the sections were incubated with appropriate FITC-labeled secondary antibodies (1:2000; Beyotime Biotechnology, China) at $37^{\circ} \mathrm{C}$ for $1 \mathrm{~h}$. Then the slides were observed and pictures were captured under a fluorescence microscope. All samples were examined by two investigators in a blind manner. Five randomly selected fields were counted, and the data represented the results in each group.

\section{Immunohistochemical (IHC) analysis on Ki67}

To evaluate epidermal proliferation, sections were stained with the proliferative marker Ki67. Briefly, sections were blocked in $10 \%$ goat normal serum for $20 \mathrm{~min}$, incubated with rabbit monoclonal antibodies (1:1000; Abcam, Britain) overnight at $4^{\circ} \mathrm{C}$. Sections were then washed and incubated with goat anti-rabbit secondary antibodies (1:2000; Beyotime Biotechnology, China) at $37^{\circ} \mathrm{C}$ for $1 \mathrm{~h}$. Subsequently, the 3-amino-9-ethyl carbazole (AEC) detection system (Bosterbio, USA) was used to visualize the staining. Sections of each group were photographed and counted under the microscope. The proliferation index was calculated using the following formula: Proliferation index $=$ Ki67 positive cells/total cells $\times$ $100 \%$.

\section{In vitro study}

\section{Cell culture}

The immortalized human epidermal keratinocyte-like cell line (HaCaT) cells were cultured in Dulbecco's modified Eagle's medium (DMEM) supplemented with 10\% fetal bovine serum (FBS) and $1 \%$ penicillin-streptomycin in a condition of $5 \% \mathrm{CO}_{2}$ at $37^{\circ} \mathrm{C}$. HaCaT cells were subcultured by trypsinization and used for subsequent processing.

\section{Optimizing ALA concentration and red light laser irradiation dose}

HaCaT cells were seeded into 96-well plates $\left(1 \times 10^{5}\right.$ cells $\left./ \mathrm{ml}\right)$. Cells treated with different ALA concentration $(0.1,0.25,0.5,0.75,1,1.5$ and $2 \mathrm{mmol} / \mathrm{L}$, respectively) were incubated in the darkness at $37^{\circ} \mathrm{C}$ for $6 \mathrm{~h}$, exposed to different doses of irradiation $(0.5$ $\mathrm{J} / \mathrm{cm}^{2}, 1.5 \mathrm{~J} / \mathrm{cm}^{2}, 3 \mathrm{~J} / \mathrm{cm}^{2}, 4.5 \mathrm{~J} / \mathrm{cm}^{2}, 6 \mathrm{~J} / \mathrm{cm}^{2}, 10 \mathrm{~J} / \mathrm{cm}^{2}$, respectively) of red light laser (635 nm wave length, $50 \mathrm{~mW} / \mathrm{cm}^{2}$ ) emitted from a semiconductor laser (XD-635AB, Shanghai Fudan-Zhangjiang Bio-Pharmaceutical Co., China). CCK-8 Kit (Beyotime Biotechnology, China) was used according to the manufacturer's instructions for cell viability assay.

\section{UVB irradiation}

HaCaT cells were cultured under a standard condition of $>70 \%$ confluency, and then irradiated by a UV fluorescent lamp (JCB35-24-01, Sigma, Shanghai, China) with a UVB dose of $60 \mathrm{~mJ} / \mathrm{cm}^{2} 2$ days after ALA-PDT or placebo pretreatment. All cells were treated with identical procedures. During the irradiation, the sham plate was shielded and the medium was removed and then covered with a thin layer of phosphate buffered saline (PBS). The intensity of UVB irradiation was measured using a UV-radiometer (Philips, The Netherlands).

\section{Cell Viability measurement}

Cell viability was measured with a CCK-8 kit (Beyotime Biotechnology, China). After the indicated treatment by ALA-PDT or UV irradiation, cells were washed for three times with PBS. Subsequently, $10 \mu \mathrm{L}$ of CCK-8 was added to each well. After incubation for $1 \mathrm{~h}$, cell density was determined through measuring the absorbance at $450 \mathrm{~nm}$ with a microplate reader (Termo Scientifc, USA).

\section{Flow cytometry analysis on apoptosis}

$\mathrm{HaCaT}$ cells that had been treated as above were harvested and washed with PBS, and double-stained by an Annexin V-FITC apoptosis detection kit (Beyotime Biotechnology, China) according to the manufacturer's instructions. Samples were incubated at room temperature for $15 \mathrm{~min}$ in the darkness with $50 \mu \mathrm{g} / \mathrm{ml}$ Annexin V-FITC and $10 \mu \mathrm{g} / \mathrm{ml} \mathrm{PI}$, and quantitatively analyzed by a FACScan flow cytometer (BD, Franklin Lakes, NJ, USA).

\section{Optical microscopic evaluation on cell morphology}

Cells were seeded into 6-well plates $\left(1 \times 10^{6}\right.$ cells/well). After the last treatment, the medium was removed and washed for three times with PBS. DMEM containing 10\% FBS was added and the cells were cultured for $24 \mathrm{~h}$. The morphological changes were observed and photographed by an optical microscopy (U-ND25-2, Olympus, Japan).

\section{Western blotting for $\mathrm{p} 53^{\text {total }}$ and $\mathrm{p} 53^{\text {Ser- }-15}$ proteins detection}

After the above mentioned treatments, HaCaT cells were subjected to Western blotting analysis. Cell proteins were extracted and quantified by a BCA kit, followed by electrophoretic separation on SDS-PAGE. After being transferred to PVDF membranes, samples were allowed to react with mouse anti-p53 antibodies (1:500; Beyotime Biotechnology, China) and rabbit anti-phospho-p53 (Ser15) antibodies (1:500; Beyotime Biotechnology, China). Then the membranes were incubated with HRP-conjugated anti-rabbit or 
anti-mouse IgG (1:4000; Beyotime Biotechnology, China) at room temperature for $2 \mathrm{~h}$. Protein expression levels of p53 total and $\mathrm{p} 53^{\text {Ser-15 }}$ were visualized using an enhanced chemiluminescence detection system, and the data of optical density were analyzed using Image-J software. $\beta$-actin was used as an internal control.

\section{Immunofluorescence analysis on CPDs}

CPDs were measured with immunofluorescence $6,24,48 \mathrm{~h}$ after the pretreatment and UVB irradiation. $\mathrm{HaCaT}$ cells cultured on the coverslips were washed twice with isotonic PBS and fixed in ice-cold $4 \%$ paraformaldehyde solution in PBS for $30 \mathrm{~min}$. The coverslips were washed for three times with PBS, and cells were permeabilized in PBS containing 0.5\% Triton X-100 for $10 \mathrm{~min}$. Then the cells were treated with $2 \mathrm{mmol} / \mathrm{L} \mathrm{HCl}$ for $30 \mathrm{~min}$ to denature cellular DNA. After blocking nonspecific antibody-binding with $10 \%$ goat normal serum for 20 min, cells were incubated with rabbit anti-CPD antibodies (1:500; Sigma, USA) overnight at $4^{\circ} \mathrm{C}$. The next day the cells were washed for three times with PBS. Then the cells were incubated with FITC-conjugated goat anti-rabbit IgG (1:1000; Beyotime Biotechnology, China) for $1 \mathrm{~h}$ at $37^{\circ} \mathrm{C}$, and then washed for three times with PBS. The nuclei were stained with DAPI (Sigma, USA) for 5 min. Finally, the samples were examined under a fluorescence microscope and analyzed by comparing the percentage of CPDs positive cells.

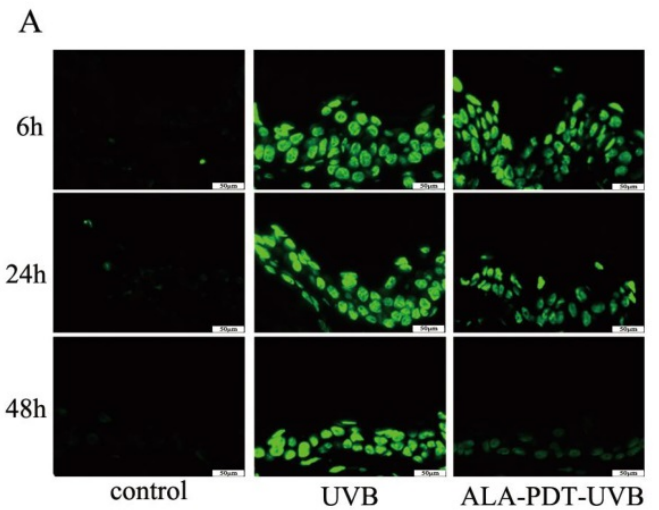

C

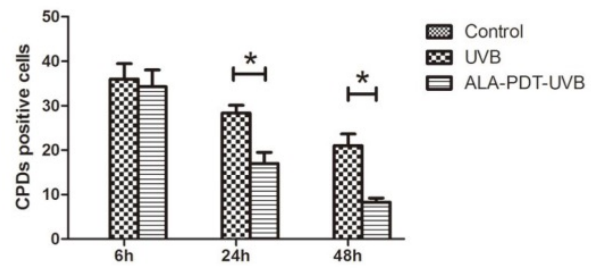

\section{Statistics}

Statistical analysis was performed by using Social Sciences (SPSS) software version 19.0. The statistical analyses were carried out by $t$-tests or One-way analysis of variance (ANOVA). $P<0.05$ was considered to indicate statistical significance. Data were expressed as mean \pm standard deviation (SD).

\section{Results}

\section{In vivo study}

\section{ALA-PDT accelerated the removal of CPDs in hairless} mice skin

We observed no CPDs-positive nuclei in unirradiated sections and the largest number of CPDs, comparable to ALA-PDT-UVB and saline-UVB group, at $6 \mathrm{~h}$ after UVB irradiation (Figure 1A). In sections pretreated with ALA-PDT (or saline) and UVB irradiation, CPDs decreased with time. However, the removal rate of CPDs was obviously higher in ALA-PDT-treated sections. At $24 \mathrm{~h}$, the number of initial CPDs-positive nuclei was $28.33 \pm 3.06$ in saline-treated epidermis, compared with $17 \pm 4.36$ in ALA-PDT-treated epidermis $(P<0.05)$ (Figure $1 C)$. At $48 \mathrm{~h}$, the number of CPDs-positive nuclei was $21 \pm$ 4.58 in saline-treated group, compared with $8.33 \pm$ 1.53 in ALA-PDT-treated group $(P<0.05)$ (Figure 1C).

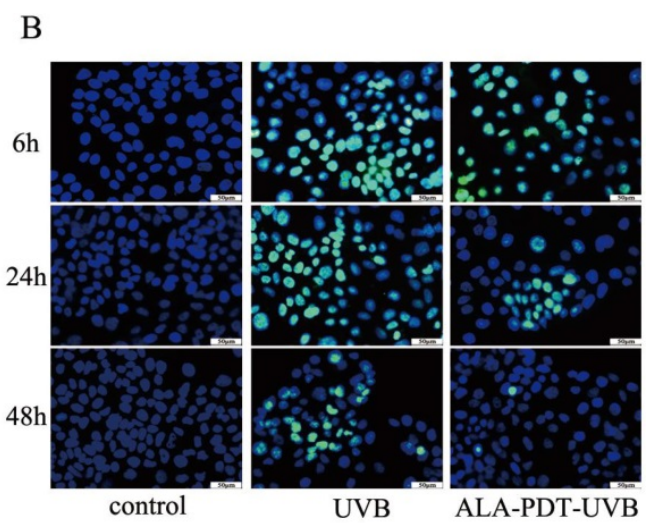

$\mathrm{D}$

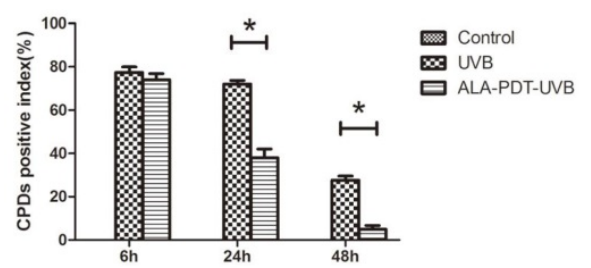

Figure 1. ALA-PDT accelerated the removal of CPDs in the dorsal skin of hairless mice and HaCaT cells after UVB irradiation. (A) CPDs positive cells in the epidermis of each group, stained by immunofluorescence staining and detected by fluorescence microscopy with $\times 400$ magnifications. (B) CPDs positive cells in HaCaT cells of each group, stained by immunofluorescence staining and detected by fluorescence microscopy with $\times 400$ magnifications. (C) The number of CPDs positive cells in the epidermis of each group. The number of CPDs positive cells in ALA-PDT-UVB groups was significantly decreased compared with UVB group at 6,24 and $48 \mathrm{~h}$ after UVB irradiation ( $P<0.05)$. (D) The number of CPDs positive cells in $\mathrm{HaCaT}$ cells of each group. The number of CPDs positive cells in ALA-PDT-UVB groups was significantly decreased compared with UVB group at 6,24 and $48 \mathrm{~h}$ after UVB irradiation $(P<0.05)$. The symbol $(*)$ indicates a significant difference $(P<0.05)$. Bar= $50 \mu \mathrm{m}, \mathrm{N}=3$. 
A
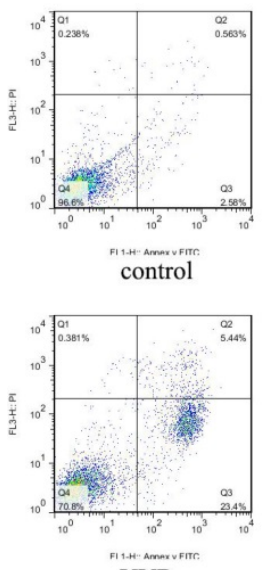

UVB

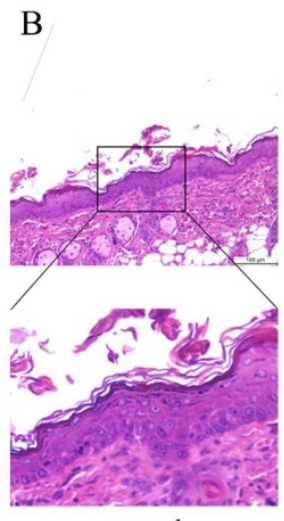

control

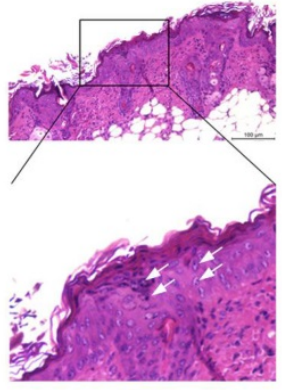

UVB

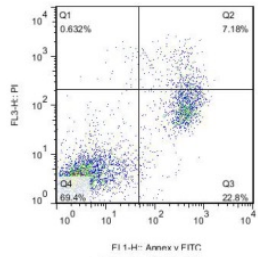

ALA-UVB

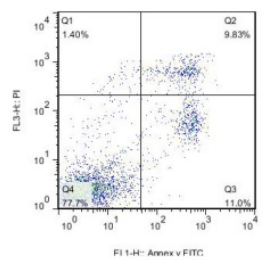

ALA-PDT-UVB
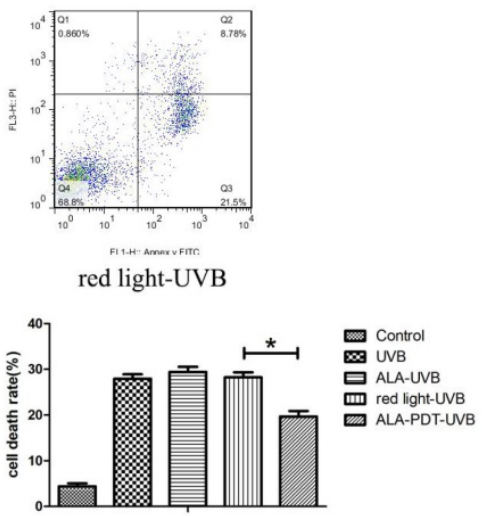

$\mathrm{C}$

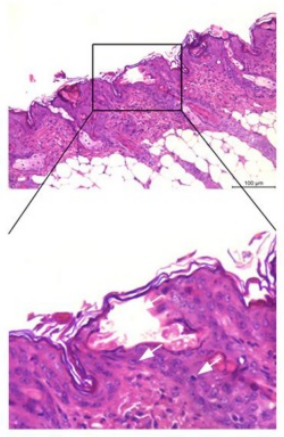

ALA-PDT-UVB

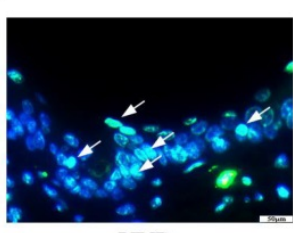

UVB

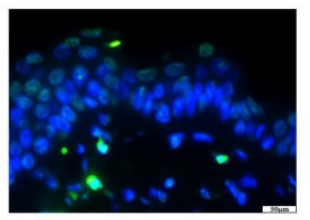

control

Figure 2. ALA-PDT suppressed UVB-induced apoptosis. (A) Evaluation of apoptosis of HaCaT cells by using annexin V/PI staining and flow cytometry. Annexin-V(-)/PI(-) cells are live cells, annexin- $\mathrm{V}(+) / \mathrm{PI}(-)$ cells are early apoptotic cells and annexin- $\mathrm{V}(+) / \mathrm{PI}(+)$ cells are late apoptotic or necrotic cells. The rate of apoptosis in ALA-PDT-UVB group was lower than that in UVB group $(P<0.05)$. (B) Sunburn cells in the epidermis of each group, stained by hematoxylin and eosin (H\&E) staining and detected by light microscopy with $\times 200$ magnifications. The number of sunburn cells in the epidermis of ALA-PDT-UVB group at $24 \mathrm{~h}$ after UVB irradiation was decreased compared with UVB group. (C) Apoptotic cells in the epidermis of each group, stained by TUNEL staining and detected by fluorescence microscope with $\times 400$ magnifications. Compared with UVB group, the number of apoptotic cells in ALA-PDT-UVB group was significantly decreased $(P<0.05)$. The symbol $(*)$ indicates a significant difference $(P<0.05)$. Bar $=100 \mu \mathrm{m}, \mathrm{N}=3$.

\section{ALA-PDT suppressed UVB-induced apoptosis of hairless mice skin cells}

Sunburn cells, a type of apoptotic keratinocytes characterized with pyknotic nuclei, condensed cytoplasm and intercellular edema, have a close correlation with UV radiation and can be used as an indicator for UV radiation-related damage. Histological evaluation of UVB-irradiated groups showed a large number of sunburn cells in the epidermis at $24 \mathrm{~h}$ after UVB irradiation (Figure 2B). The number of sunburn cells in the epidermis of ALA-PDT-treated group at $24 \mathrm{~h}$ after UVB irradiation were decreased compared with those in the UVB group (Figure 2B). The apoptotic cells were stained green by TUNEL staining. The non-irradiated group showed no TUNEL staining. UVB-irradiated groups showed TUNEL-positive apoptotic cells. Compared with UVB group, the proportion of apoptotic cells in ALA-PDT-treated group was significantly decreased $(P<0.05)$ (Figure 2C).

\section{ALA-PDT inhibited UVB-induced hyperproliferation of hairless mice skin cells}

To determine whether ALA-PDT can inhibit UVB-induced hyperproliferation, we evaluated the number of Ki67 positive nuclei in saline- or ALA-PDT-treated and then UVB-irradiated hairless mice skin. In unirradiated skin, the number of Ki67 positive nuclei was low (Figure 3A). No significant difference in the number of Ki67 positive nuclei was detected in saline- vs. ALA-PDT-treated skin at $6 \mathrm{~h}$ and $24 \mathrm{~h}$ after UVB irradiation. However, by $48 \mathrm{~h}$ in ALA-PDT-UVB group, the number of Ki67 positive nuclei was significantly less than in UVB group $(P<$ 0.05) (Figure 3B).

\section{In vitro study}

ALA-PDT protected $\mathrm{HaCaT}$ cells against UV-induced cell viability impairment

To observe whether ALA-PDT leads to the apoptosis of HaCaT cells, we performed cck- 8 assay to quantify the cell viability. Results showed that 0.5 
mmol/L of ALA and $3 \mathrm{~J} / \mathrm{cm}^{2}$ of red light did not affect the vitality of cells, and compared with the control group, the difference was not significant $(P>$ 0.05) ( Figure 4B). HaCaT cells viability of UVB group was significantly lower than that of ALA-PDT-treated group $(P<0.05)$, indicating that ALA-PDT significantly decreased UVB-induced cytotoxicity (Figure 4B).

\section{ALA-PDT accelerated the removal of CPDs in $\mathrm{HaCaT}$ cells}

After UVB irradiation, the CPDs-positive cells were stained with immunofluorescence staining. No CPDs-positive cells were found out of HaCaT cells in the control group. UVB-irradiated groups showed a large number of CPDs-positive cells, with the peak at $6 \mathrm{~h}$ after UVB irradiation. Then, at $24 \mathrm{~h}$ and $48 \mathrm{~h}$ after UVB irradiation, the proportions of CPDs-positive cells in ALA-PDT pretreatment group were

A

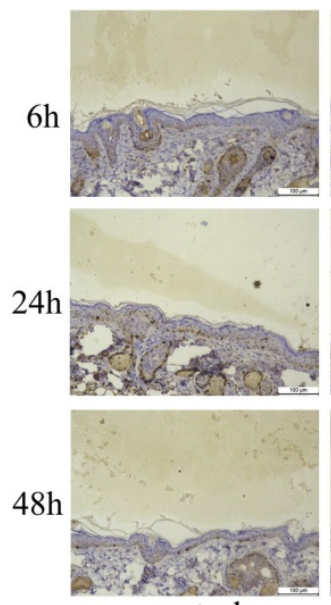

control

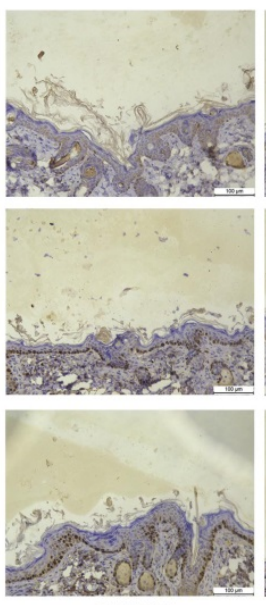

UVB

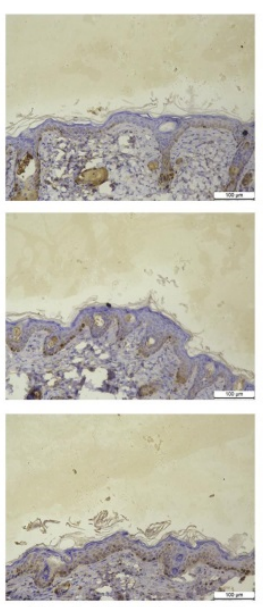

ALA-PDT-UVB
B

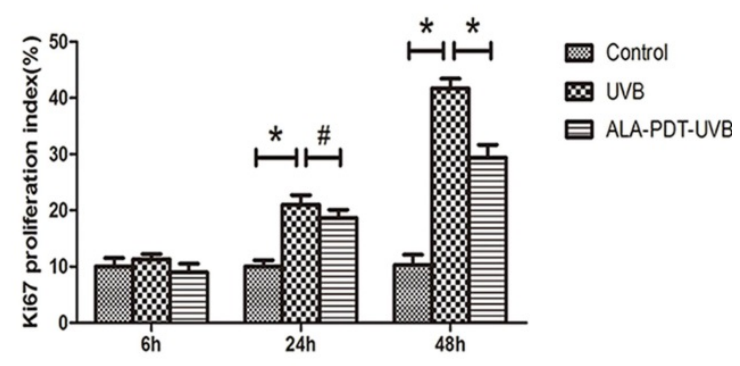

significantly decreased compared with UVB group ( $P$ $<0.05$ )( Figure 1B, D).

ALA-PDT increased the levels of p53total and p53 Ser-15 proteins in $\mathrm{HaCaT}$ cells

To determine whether ALA-PDT can increase the levels of p53 protein level and serine-15 phosphorylation in vitro, we processed $\mathrm{HaCaT}$ cells for both $\mathrm{p} 53^{\text {total }}$ and $\mathrm{p} 53^{\mathrm{Ser}-15}$ Western blotting detection. The results showed that UVB-irradiated groups had significantly higher level of p53total and p535er-15 expression compared with unirradiated group $(P<0.05)$ (Figure $5 \mathrm{~A})$. Further, as shown in Figure 5B, C, D, the expression of p53 total and p535er-15 in the ALA-PDT-treated samples were significantly higher than those in samples untreated with ALA-PDT $(P<0.05)$.

Figure 3. ALA-PDT pretreatment inhibited UVB-induced hyperproliferation in hairless mice skin. (A) Ki67 protein expression in the epidermis of each group at 6,24 , and $48 \mathrm{~h}$ after UVB irradiation, stained by immunohistochemical staining and detected by light microscopy with $\times 200$ magnifications. (B) When compared with the UVB group, the number of Ki67 positive cells decreased in ALA-PDT-UVB group at $48 \mathrm{~h}$ after UVB irradiation $(P<0.05)$. The symbol $(*)$ indicates a significant difference $(P<0.05)$. Bar= $100 \mu \mathrm{m}, \mathrm{N}=3$.

A

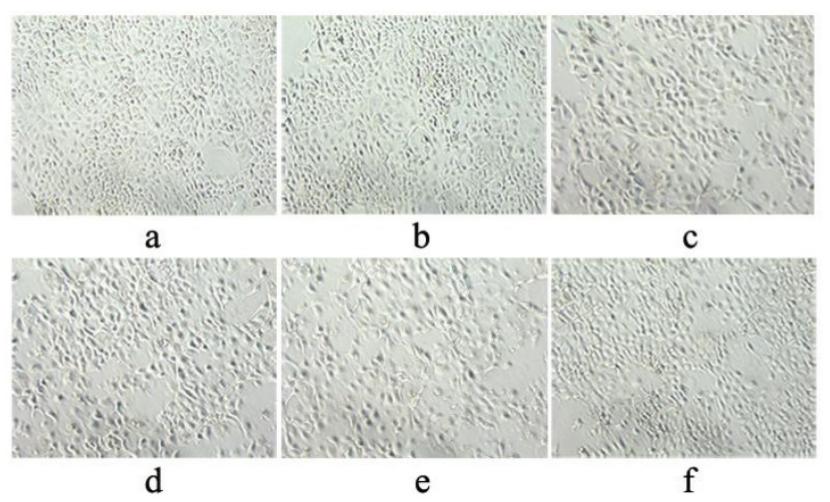

B

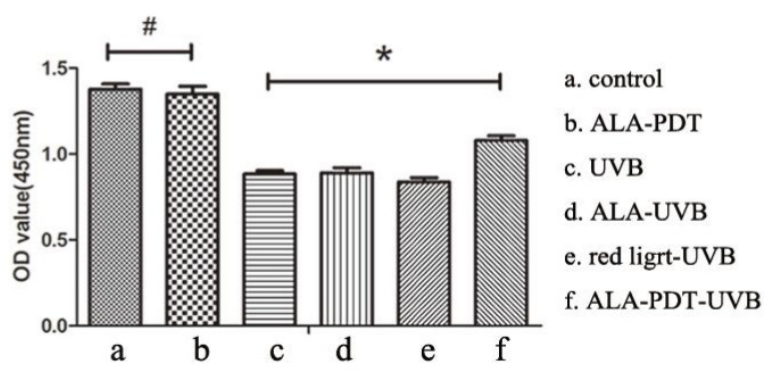

Figure 4. ALA-PDT protected HaCaT cells from UV-induced cell viability impairment. (A) Inverted phase contrast microscope observation of HaCaT cells. Cells of control group had the same shapes, clear boundaries, close arrangement. UVB group showed decreased cell number, decreased cell adhesion, increased intercellular space, rounded or irregular shapes, cell debris, and a large number of suspended cells. However, the cell morphology in ALA-PDT-UVB group was significantly normalized compared with UVB group. (B) Cell viability was analyzed by CCK-8. ALA $(0.5 \mathrm{mmol} / \mathrm{L})$ and low level of red light $\left(3 \mathrm{~J} / \mathrm{cm}^{2}\right)$ had no effect on cell viability $(P>0.05)$. Cell viability of ALA-PDT-UVB group was higher than that of UVB group $(P<0.05)$. The symbol $\left(^{*}\right)$ indicates a significant difference $(P<0.05)$. 
A

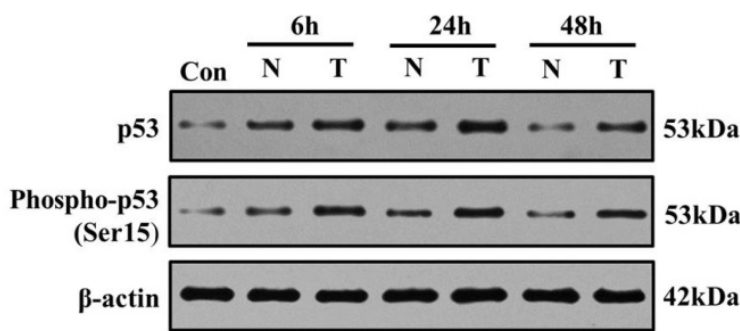

$\mathrm{B}$

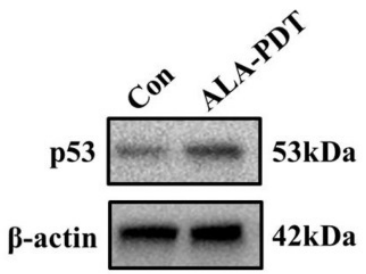

$\mathrm{D}$

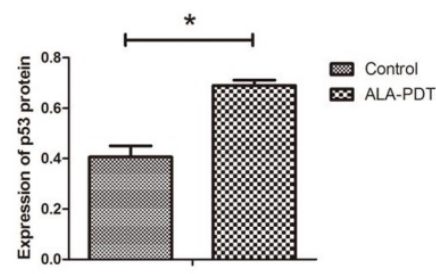

Figure 5. ALA-PDT up-regulated and activated $\mathrm{p} 53$ in HaCaT cells. (A) Western blotting for detection of $\mathrm{p} 53^{\text {total }}$ and $\mathrm{p} 53^{\text {ser- }-15} \mathrm{protein}$ in $\mathrm{HaCaT}$ cells of each group at 6,24 , and $48 \mathrm{~h}$. Con: control group, N: UVB group, T: ALA-PDT-UVB group. (B) Expression of p53total in HaCaT cells at $24 \mathrm{~h}$ after ALA-PDT treatment (0.5 mmol/L + $\left.3 \mathrm{~J} / \mathrm{cm}{ }^{2}\right)$. (C) (D) Protein expressions were quantified by $\beta$-actin as a control. The ratio of gray scale values represents the ratio of the amount of protein to interest/actin. The symbol $(*)$ indicates a significant difference $(P<0.05)$. $\mathrm{N}=3$.

\section{Inverted phase contrast microscope observation}

Inverted microscope showed cells of control group had the same shapes, clear boundaries and close arrangement. UVB group showed a decreased cell number decreased cell adhesion, increased intercellular space, rounded or irregular shapes, debris, and a large number of suspended cells. However, the cell morphology of ALA-PDT group was significantly normalized compared with UVB group (Figure 4A).

\section{ALA-PDT suppressed UVB-induced apoptosis in $\mathrm{HaCaT}$ cells}

Annexin-V (-) / PI (-) cells are live cells, Annexin-V (+) / PI (-) cells are early-stage apoptotic cells and annexin-V $(+) /$ PI $(+)$ cells are late-stage apoptotic or necrotic cells. Apoptosis rate was expressed as a percentage of apoptotic cells in total cells. As shown in Figure 2A, the percentage of apoptotic cells in ALA-PDT pretreatment group was $27.95 \pm 1.71$, significantly lower than $19.69 \pm 2.09$ in the UVB group $(P<0.05)$.

\section{Discussion}

Due to its ability of enhancing dermal remodeling and resolves chronic inflammation, ALA-PDT has been used to treat skin photodamages, including actinic keratoses, squamous cell carcinomas, basal cell carcinomas and photoaging [17, 20, 29-31]. Inge Seubring et al. treated AK patients with "lesion-by-lesion" methyl aminolevulinate photodynamic therapy (MAL-PDT) and field
MAL-PDT. Nine months later, field MAL-PDT significantly reduced AK lesions compared with lesion-by-lesion MAL-PDT[32]. ALA and its methyl esters (methyl 5-aminolevulinate) are the most effective topical photosensitizers approved for treating actinic keratoses[21, 22]. ALA esters can notably improve skin uptake[17, 33, 34], but the porphyrin fluorescence of ALA and ALA methyl esters showed the same microscopical spatial distribution[35]. As to the ability of reducing AK, ALA and ALA esters showed no difference. Although a large number of recent studies have proven that ALA-PDT can prevent skin tumors, the underlying mechanisms are unknown. To explore these mechanisms, we carried out in vivo animal and in vitro cell experiments.

ALA-PDT, functioning as photosensitizers, interacts with light and oxygen, producing reactive oxygen species (ROS) that plays a leading role in the mechanism of ALA-PDT[36, 37]. Low-level ROS can act as cellular signaling messengers by modifying protein structures and functions, activating dermal fibroblasts and increasing cellular proliferation, just as in treating skin rejuvenation[38]. Through disrupting cellular processes by non-specifically attacking proteins, lipids and DNA, high-level ROS can decrease cellular proliferation and increase cytotoxicity, just as in treating skin cancers[39]. In our study, low concentration of ALA $(0.5 \mathrm{mmol} / \mathrm{L})$ and low level of red light $\left(3 \mathrm{~J} / \mathrm{cm}^{2}\right)$ had no effect on cell viability, though ROS production was induced.

UVB irradiation directly damages the skin's cellular DNA, through which CPDs and 6-4pps are 
generated. Outnumbering 6-4pps and more difficult to be repaired, CPDs are always regarded as the principal product of photodamage[10, 40]. CPDs, if not removed by the nucleotide excision repair pathway in time, may lead to DNA mutation[41]. Therefore, detecting the generation and removal of UVB-induced CPDs is useful for assessing the severity of DNA damage and repair. In this study, we found that UVB-induced CPDs in ALA-PDT group were removed more rapidly than UVB group. Some antioxidants, such as polyphenols and oligopeptides, can promote the removal of CPDs[42, 43] mainly through absorbing UVB and clearing oxygen free radicals, and reduce the damage caused by oxygen free radicals in CPDs nucleotide excision repair pathway.[42] Barbara A. Gilchrest et al. previously demonstrated T-oligos accelerated the clearance of CPDs, through a protective DNA damage response induced by activation of P53[44].

Inducible DNA repair, termed as SOS response, was first found in bacteria. In essence, following acute sublethal DNA damage is a transient increase of DNA repair rate[45]. Barbara A. Gilchrest et al. demonstrated the existence of inducible DNA damage response that increased DNA repair capacity and reduced the impact of environmental carcinogens [44, 46, 47]. They reported that in vitro thymidine dinucleotide activated p53 and increased the ability of skin cells (endogenous DNA, to be specific) to repair subsequent UV-induced DNA damage[48].

Further investigation on the expression of p53 after UVB radiation was conducted to substantiate the inducible DNA damage response of ALA-PDT after UVB radiation. As a transcription factor, p53 protein regulates the expressions of a series of downstream target genes to maintain genomic integrity through transient cell cycle arrest for DNA repair, and if the DNA damage could not be repaired correctly, p53 would induce programmed cell death or apoptosis[15]. In our study, after HaCaT cells were pretreated with ALA-PDT and then irradiated with UVB, ALA-PDT induced and activated p53 within 24 $h$ and significantly increased p53 after UVB exposure. This further indicates that ALA-PDT may induce a protective DNA damage response through activating P53.

To verify whether ALA-PDT improved the skin cells' ability of repairing damaged DNA, we observed the epidermal DNA damage through strand breaks (TUNEL assay) and sunburn cells (H\&E). Exposure to short-term and high-dose ultraviolet radiation can damage the DNA of skin cells and induce the apoptosis of keratinocytes, morphologically turning the later into sunburn cells. Exposure duration, UV dose and light work together to decide the development of sunburn cells. After UVB (200 $\mathrm{mJ} / \mathrm{cm}^{2}$ ), it needs at least $24 \mathrm{~h}$ for sunburn cell to come into being[49]. Our previous study also found that the formation of sunburn cells in human epidermis reached the highest level $24 \mathrm{~h}$ after UVB $\left(180 \mathrm{~mJ} / \mathrm{cm}^{2}\right)$ irradiation[42]. DNA strands break prior to the formation of morphologically distinct sunburn cells[50]. These explained why only a few sunburn cells were observed by H\&E staining $24 \mathrm{~h}$ after UVB, but TUNEL detected a large number of apoptotic cells. More cell experiments showed that ALA-PDT increased cell viability and decreased apoptosis after UVB irradiation. These results indicate that ALA-PDT reduces the generation of apoptotic cells.

UV irradiation results in a dose-dependent arrest of epidermal proliferation and then hyperplasia, which exerts a protective effect by prolonging the path of photons to putative stem cells in the basal layer of the epidermis during UV exposure[41, 51, 52]. However, if DNA replication and cell division occur when DNA repair is still on, the risk of mutation rises.[10] Simin Arad et al. reported that T-oligos-induced protective DNA damage response could inhibit UV-induced epidermal proliferation[44]. Consistent with this, we also found that ALA-PDT significantly inhibited the epidermal proliferation.

In conclusion, our study demonstrates that ALA-PDT can induce a protective DNA damage response through activating p53 and enhancing DNA repair capacity. This enhanced repair capacity can inhibit epidermal proliferation, reduce the generation of apoptotic cells and accelerate the removal of CPDs, which work together to protect skin cells against UVB-induced photodamage. However, whether ALA-PDT can prevent sunlight-induced tumors in vitro experiments has not been confirmed. In addition, the specific method of using ALA-PDT to prevent sunlight-induced diseases remains to be created.

\section{Abbreviations}

UV: Ultraviolet; ALA-PDT: 5-aminolaevulinic acid-based photodynamic therapy; AK: actinic keratosis; CPDs: cyclobutane pyrimidine dimers; CCK: Cell Counting Kit; ROS: reactive oxygen species; FBS: fetal bovine serum; PBS: phosphate buffered saline; OD: Optical density; SD: standard deviation; H\&E: haematoxylin and eosin; DAPI: 4',6-diamidino-2-phenylindole; DMEM: Dulbecco's modified Eagle's medium.

\section{Acknowledgements}

This work was financially supported by grants from the China National Natural Science Foundation (81573072 and 81301384), and the Priority Academic 
Program Development (PAPD) of Jiangsu Higher Education Institutions.

\section{Funding}

This work was supported by Grants from the China National Natural Science Foundation (81573072 and 81703142), and the Priority Academic Program Development (PAPD) of Jiangsu Higher Education Institutions (JX10231801). Bingrong ZHOU is funded by the project of key youth medical talent of Jiangsu Province (QNNRC 2016583) and outstanding young backbone teachers of Nanjing Medical University (2017).

\section{Author Contributions}

Conceived and designed the experiments: Hui Hua, Jia-wei Cheng, Wen-bo Bu, Bing-rong Zhou, Dan Luo. Performed the experiments: Hui Hua, Jia-wei Cheng. Contributed reagents/materials/ analysis tools: Juan Liu, Wei-wei Ma, Na Ni. Analysed the data: Hui Hua, Jia-wei Cheng, Jian Shi. Wrote and edited the paper: Hui Hua, Jia-wei Cheng, Bing-rong Zhou.

\section{Competing Interests}

The authors have declared that no competing interest exists.

\section{References}

1. Lomas A, Leonardi-Bee J, Bath-Hextall F. A systematic review of worldwide incidence of nonmelanoma skin cancer. The British journal of dermatology. 2012; 166: 1069-80.

2. Xiang F, Lucas R, Hales S, Neale R. Incidence of nonmelanoma skin cancer in relation to ambient UV radiation in white populations, 1978-2012: empirical relationships. JAMA dermatology. 2014; 150: 1063-71.

3. Tripp MK, Watson M, Balk SJ, Swetter SM, Gershenwald JE. State of the science on prevention and screening to reduce melanoma incidence and mortality: The time is now. CA: a cancer journal for clinicians. 2016.

4. Marionnet C, Tricaud C, Bernerd F. Exposure to non-extreme solar UV daylight: spectral characterization, effects on skin and photoprotection. International journal of molecular sciences. 2014; 16: 68-90.

5. Seité S, Colige A, Piquemal-Vivenot $\mathrm{P}$, Montastier C, Fourtanier A, Lapière C, et al. A full-UV spectrum absorbing daily use cream protects human skin against biological changes occurring in photoaging. Photodermatology Photoimmunology \& Photomedicine. 2000; 16: 147-55.

6. Rigby CM, Roy S, Deep G, Guillermo-Lagae R, Jain AK, Dhar D, et al. Role of p53 in silibinin-mediated inhibition of ultraviolet B radiation-induced DNA damage, inflammation and skin carcinogenesis. Carcinogenesis. 2017; 38: 40-50

7. Gilchrest BA. Photoaging. The Journal of investigative dermatology. 2013; 133: E2-6.

8. Sklar LR, Almutawa F, Lim HW, Hamzavi I. Effects of ultraviolet radiation, visible light, and infrared radiation on erythema and pigmentation: a review. Photochemical \& photobiological sciences : Official journal of the European Photochemistry Association and the European Society for Photobiology. 2013; 12: 54-64.

9. Pleasance ED, Cheetham RK, Stephens PJ, McBride DJ, Humphray SJ, Greenman $\mathrm{CD}$, et al. A comprehensive catalogue of somatic mutations from a human cancer genome. Nature. 2010; 463: 191-6.

10. Ravanat JL, Douki T, Cadet J. Direct and indirect effects of UV radiation on DNA and its components. Journal of photochemistry and photobiology B, Biology. 2001; 63: 88-102.

11. Afaq F, Katiyar SK. Polyphenols: skin photoprotection and inhibition of photocarcinogenesis. Mini reviews in medicinal chemistry. 2011; 11: 1200-15.

12. Afaq F. Natural agents: cellular and molecular mechanisms of photoprotection. Archives of biochemistry and biophysics. 2011; 508: 144-51.

13. Marrot L, Meunier JR. Skin DNA photodamage and its biological consequences. Journal of the American Academy of Dermatology. 2008; 58: S139-48.
14. Ford JM. Regulation of DNA damage recognition and nucleotide excision repair: another role for p53. Mutation research. 2005; 577: 195-202.

15. Mello SS, Attardi LD. Deciphering p53 signaling in tumor suppression. Current opinion in cell biology. 2017; 51: 65-72

16. Kim CH, Chung CW, Choi KH, Yoo JJ, Kim DH, Jeong YI, et al. Effect of 5-aminolevulinic acid-based photodynamic therapy via reactive oxygen species in human cholangiocarcinoma cells. International journal of nanomedicine. 2011; 6: 1357-63.

17. Zhang LW, Fang YP, Fang JY. Enhancement techniques for improving 5-aminolevulinic acid delivery through the skin. Dermatologica Sinica. 2011; 29: 1-7.

18. Friedmann DP, Goldman MP, Fabi SG, Guiha I. Multiple sequential light and laser sources to activate aminolevulinic acid in the treatment of photodamage: A retrospective study. Journal of cosmetic and laser therapy : official publication of the European Society for Laser Dermatology. 2015; 17: 252-8.

19. Ji J, Zhang LL, Ding HL, Wang HW, Huang Z, Wang XX, et al. Comparison of 5-aminolevulinic acid photodynamic therapy and red light for treatment of photoaging. Photodiagnosis and photodynamic therapy. 2014; 11: 118-21.

20. Ge X, Liu J, Shi Z, Jing L, Yu N, Zhang X, et al. Inhibition of MAPK signaling pathways enhances cell death induced by 5-Aminolevulinic acid-photodynamic therapy in skin squamous carcinoma cells. European journal of dermatology : EJD. 2016; 26: 164-72.

21. Zhou BR, Zhang LC, Permatasari F, Liu J, Xu Y, Luo D. ALA-PDT elicits oxidative damage and apoptosis in UVB-induced premature senescence of human skin fibroblasts. Photodiagnosis and photodynamic therapy. 2016; 14: 47-56

22. Gozali MV, Yi F, Zhang JA, Liu J, Wu HJ, Xu Y, et al. Photodynamic therapy inhibit Fibroblast Growth Factor-10 induced keratinocyte differentiation and proliferation through ROS in Fibroblast Growth Factor Receptor-2b pathway. Scientific reports. 2016; 6: 27402.

23. Pei S, Kaminska ECN, Tsoukas MM. Treatment of Actinic Keratoses: A Randomized Split-Site Approach Comparison of Sequential 5-Fluorouracil and 5-Aminolevulinic Acid Photodynamic Therapy to 5-Aminolevulinic Acid Photodynamic Monotherapy. Dermatol Surg. 2017; 43: 1170-5.

24. Bissonnette R. Chemopreventative thoughts for photodynamic therapy. Dermatologic clinics. 2007; 25: 95-100.

25. Grose D, Anseline W, Smith P. Photodynamic therapy for the prevention of skin cancer. Dermatol Surg. 2014; 40: 1441-2.

26. Stender IM, Bech-Thomsen N, Poulsen T, Wulf HC. Photodynamic therapy with topical delta-aminolevulinic acid delays UV photocarcinogenesis in hairless mice. Photochemistry and photobiology. 1997; 66: 493-6.

27. Caty V, Liu Y, Viau G, Bissonnette R. Multiple large surface photodynamic therapy sessions with topical methylaminolaevulinate in PTCH heterozygous mice. The British journal of dermatology. 2006; 154: 740-2.

28. Goldberg LH, Landau JM, Moody MN, Marquez D, Jih M, Kimyai-Asadi A, et al. Evaluation of the chemopreventative effects of ALA PDT in patients with multiple actinic keratoses and a history of skin cancer. Journal of drugs in dermatology : JDD. 2012; 11: 593-7.

29. Qidwai A, Khan S, Md S, Fazil M, Baboota S, Narang JK, et al. Nanostructured lipid carrier in photodynamic therapy for the treatment of basal-cell carcinoma. Drug delivery. 2016; 23: 1476-85.

30. Wang X, Ji I, Zhang H, Fan Z, Zhang L, Shi L, et al. Stimulation of dendritic cells by DAMPs in ALA-PDT treated SCC tumor cells. Oncotarget. 2015; 6: 44688-702.

31. Sjerobabski MI, Situm M. Photorejuvenation--topical photodynamic therapy as therapeutic opportunity for skin rejuvenation. Collegium Antropologicum. 2014; 38: 1245-8

32. Seubring I, Groenewoud JMM, Gerritsen MP. Comparison of "Lesion-by-Lesion" and Field Photodynamic Therapy in the Prevention of Actinic Keratoses: A Randomized, Split-Face, Single-Blind Pilot Study. Dermatology. 2016; 232: 708-14

33. Gaullier J, Berg $\mathrm{K}$, Peng $\mathrm{O}$, Anholt $\mathrm{H}$, Selbo $\mathrm{PK}$, Ma $\mathrm{L}$, et al. Use of 5-Aminolevulinic Acid Esters to Improve Photodynamic Therapy on Cells in Culture. Cancer Res. 1997; 57: 1481-6.

34. Angell-Petersen E, Sorensen R, Warloe T, Soler AM, Moan J, Peng Q, et al. Porphyrin formation in actinic keratosis and basal cell carcinoma after topical application of methyl 5-aminolevulinate. The Journal of investigative dermatology. 2006; 126: 265-71.

35. de Bruijn HS, Meijers C, van der Ploeg-van den Heuvel A, Sterenborg HI, Robinson DJ. Microscopic localisation of protoporphyrin IX in normal mouse skin after topical application of 5-aminolevulinic acid or methyl 5-aminolevulinate. Journal of photochemistry and photobiology B, Biology. 2008: 92: 91-7.

36. Zhou Z, Song J, Nie L, Chen X. Reactive oxygen species generating systems meeting challenges of photodynamic cancer therapy. Chemical Society reviews. 2016; 45: 6597-626.

37. Schumacker PT. Reactive oxygen species in cancer: a dance with the devil. Cancer cell. 2015; 27: 156-7.

38. Jang YH, Koo GB, Kim JY, Kim YS, Kim YC. Prolonged activation of ERK contributes to the photorejuvenation effect in photodynamic therapy in human dermal fibroblasts. Journal of Investigative Dermatology. 2013; 133: 2265-75

39. Takahashi J, Misawa M, Murakami M, Mori $T$, Nomura $K$, Iwahashi $H$. 5-Aminolevulinic acid enhances cancer radiotherapy in a mouse tumor model. SpringerPlus. 2013; 2: 602. 
40. Kobayashi N, Katsumi S, Imoto K, Nakagawa A, Miyagawa S, Furumura M, et al. Quantitation and Visualization of Ultraviolet-Induced DNA Damage Using Specific Antibodies: Application to Pigment Cell Biology. Pigment Cell Research. 2001; 14: 94-102.

41. Nakanishi M, Niida H, Murakami H, Shimada M. DNA damage responses in skin biology--implications in tumor prevention and aging acceleration. Journal of dermatological science. 2009; 56: 76-81.

42. Zhou BR, Ma LW, Liu J, Zhang JA, Xu Y, Wu D, et al. Protective Effects of Soy Oligopeptides in Ultraviolet B-Induced Acute Photodamage of Human Skin. Oxidative medicine and cellular longevity. 2016; 2016: 5846865.

43. Hu S, Chen F, Wang M. Photoprotective effects of oxyresveratrol and Kuwanon $\mathrm{O}$ on DNA damage induced by UVA in human epidermal keratinocytes. Chemical research in toxicology. 2015; 28: 541-8.

44. Arad S, Konnikov N, Goukassian DA, Gilchrest BA. T-oligos augment UV-induced protective responses in human skin. FASEB journal : official publication of the Federation of American Societies for Experimental Biology. 2006; 20: 1895-7.

45. Radman M. SOS repair hypothesis: phenomenology of an inducible DNA repair which is accompanied by mutagenesis. Basic life sciences. 1975; 5A: 355-67.

46. Gilchrest BA. Telomere-Based Protective Responses to DNA Damage. The journal of investigative dermatology Symposium proceedings. 2015; 17: 15-6.

47. Arad S, Konnikov N, Goukassian DA, Gilchrest BA. Quantification of inducible SOS-like photoprotective responses in human skin. The Journal of investigative dermatology. 2007; 127: 2629-36.

48. Eller MS, Maeda T, Magnoni C, Atwal D, Gilchrest BA. Enhancement of DNA repair in human skin cells by thymidine dinucleotides: evidence for a p53-mediated mammalian SOS response. Proceedings of the National Academy of Sciences of the United States of America. 1997; 94: 12627-32.

49. Svobodova AR, Galandakova A, Sianska J, Dolezal D, Lichnovska R, Ulrichova J, et al. DNA damage after acute exposure of mice skin to physiological doses of UVB and UVA light. Archives of dermatological research. 2012; 304: 407-12.

50. Archana M, Yogesh TL, Kumaraswamy KL. Various methods available for detection of apoptotic cells--a review. Indian Journal of Cancer. 2013; 50: 274-83.

51. Kim AL, Athar M, Bickers DR, Gautier J. Ultraviolet-B-induced G1 arrest is mediated by downregulation of cyclin-dependent kinase 4 in transformed keratinocytes lacking functional p53. Journal of Investigative Dermatology. 2002; 118: 818-24.

52. Del Bino S, Vioux C, Rossio-Pasquier P, Jomard A, Demarchez M, Asselineau $\mathrm{D}$, et al. Ultraviolet $\mathrm{B}$ induces hyperproliferation and modification of epidermal differentiation in normal human skin grafted on to nude mice. The British journal of dermatology. 2004; 150: 658-67. 